\title{
Oct-4 is associated with gastric cancer progression and prognosis
}

\author{
Wen-Li Jiang' \\ Peng-Fei Zhang ${ }^{2}$ \\ Guo-Feng $\mathrm{Li}^{\prime}$ \\ Jian-Hua Dong' \\ Xue-Song Wang' \\ Yuan-Yu Wang ${ }^{3}$ \\ 'Department of Surgery, Juxian \\ People's Hospital, ${ }^{2}$ Department of \\ Surgery, Rizhao People's Hospital of \\ Traditional Chinese Medicine, Rizhao, \\ ${ }^{3}$ Department of Gastrointestinal \\ Surgery, Zhejiang Provincial \\ People's Hospital, Hangzhou, \\ People's Republic of China
}

This article was published in the following Dove Press journal: OncoTargets and Therapy

27 January 2016

Number of times this article has been viewed

Aim: To investigate the clinical significance of Oct-4 in the development and progression of gastric cancer.

Methods: Immunohistochemistry was used to analyze Oct-4 expression in 412 gastric cancer cases. Oct-4 protein levels were upregulated in gastric cancer tissues compared with adjacent noncancerous tissues.

Results: Positive expression of Oct-4 correlated with age, depth of invasion, Lauren classification, lymph node metastasis, distant metastasis, and TNM stage. In stages I, II, and III, the 5 -year survival rate of patients with high expression of Oct-4 was significantly lower than that in patients with low expression of Oct-4. In stage IV, Oct-4 expression did not correlate with the 5-year survival rate. Furthermore, multivariate analysis suggested that the depth of invasion, lymph node metastasis, distant metastasis, TNM stage, and upregulation of Oct-4 were independent prognostic factors of gastric cancer.

Conclusion: Oct-4 protein is a useful marker in predicting tumor progression and prognosis. Keywords: gastric carcinoma, invasion, metastasis, survival rate

\section{Introduction}

Gastric cancer is the second leading cause of cancer-related mortality worldwide. Despite recent advances in surgical techniques and chemotherapy, the overall 5-year survival rate in the People's Republic of China is still only 40\%. Most gastric cancer is diagnosed as stage III or IV, and the rate of lymph node metastasis is high $(50 \%-75 \%) .{ }^{1} \mathrm{~A}$ recent study suggests that Oct-4 could be involved in the development of certain tumors. Oct-4 is essential for the identity of the pluripotent founder cell population in the mammalian embryo..$^{2-4}$ Oct-4 was recently identified to be associated with tumorigenesis and malignant transformation of cancers. Oct-4 expression was significantly increased from normal epithelium (both ovarian epithelium and fallopian tube epithelium) to benign and borderline cystadenoma to carcinoma in the serous lesion subgroups. ${ }^{5}$ Oct-4 was expressed in hepatocellular carcinoma (HCC) cell lines and tumor specimens of HCC. ${ }^{6}$ Expression of Oct-4 in metaplastic pancreatic ducts was significantly stronger than in normal acini and pancreatic carcinoma. ${ }^{7}$ Oct- 4 was significantly higher in sporadic colorectal cancer compared with adjacent normal colonic epithelium. ${ }^{8}$ It has been shown that Oct-4 may play a role in tumorigenesis. However, little is known regarding the efficacy of Oct-4 as a potential biomarker for cancer; thus, we investigated its expression in gastric cancer and its relationship with gastric cancer.

\section{Materials and methods Patients and tissue samples}

Gastric cancer tissues were collected from the gastrectomy specimens of 412 patients (male:female 284:128; median age, 62 years; range, 30-85 years) treated at the 
Department of Gastrointestinal Surgery, Zhejiang Provincial People's Hospital and Juxian People's Hospital between January 2001 and January 2010. Tissues were formalin-fixed and paraffin-embedded. All patients were followed up for over 5 years. The follow-up deadline was December 2013. The survival time was measured from the date of surgery to the follow-up deadline, or date of death (usually the result of carcinoma recurrence or metastasis). Cancer was found in the cardia, body, and antrum in 84, 154, and 174 cases, respectively. According to the World Health Organization histological classification of gastric carcinoma formulated in 2002, there were 39 cases of distant metastasis. Eighty noncancerous human gastric tissue samples were obtained from gastrectomy of adjacent gastric cancer margins $(>5 \mathrm{~cm})$. Chemotherapy (fluorouracil, cisplatin, and tetrahydrofolic acid) was given to patients with advanced-stage disease after surgery, but none of the patients received radiation treatment. This study was approved by the Ethics Committee of Zhejiang Provincial People's Hospital.

\section{Tissue microarrays}

Blocks (412 cancer samples and 80 noncancer tissue samples) were prepared as previously described., ${ }^{9} 10$ Sections (4 mm) were cut from each tissue array block, deparaffinized, and dehydrated.

\section{Immunohistochemistry}

Immunohistochemical analysis was carried out to determine altered protein expression in the 80 noncancerous human gastric tissue controls and 412 human gastric cancer tissues. Rabbit anti-Oct-4 was provided by Santa Cruz (Mountain View, CA, USA). Cytoplasmic and nuclear Oct-4 was stained buffy brown. The degree of immunostaining was scored independently by two observers based on the proportion of positively stained tumor cells and the staining intensity. ${ }^{11,12}$ The staining index was calculated as the staining intensity score to the proportion of positive tumor cells. The cut-off value for high and low expression levels was chosen based on a measure of heterogeneity using the log-rank test with respect to overall survival: a staining index score of $\geq 4$ indicates high Oct-4 expression and a staining index score of $\leq 3$ indicates low Oct- 4 expression.

\section{Statistical analysis}

All statistical analyses were performed using SPSS 16.0 software (Chicago, IL, USA). Survival curves were estimated using the Kaplan-Meier method, and the log-rank test was used to compare differences between the curves. We assessed the prognostic value of protein expression levels by Cox proportional hazards regression model.

\section{Results}

\section{The expression of Oct-4 in gastric cancer and noncancer mucosa}

Oct-4 was detected in 26/80 (32.5\%) nontumor mucosae, and all samples expressed the protein at low levels. Oct-4 was expressed in 310/412 (75.2\%) gastric cancer cases, and high Oct-4 expression was detected in 252/412 (61.17\%) tumors. Oct-4 was mainly localized in the cytoplasm, with some localization in the nuclei of cancer cells (Figure 1).

\section{Expression of Oct-4 and clinicopathological features}

The expression of Oct-4 was related to age, differentiation, invasion, Lauren classification, lymph node metastasis, distant metastasis, and TNM stage $(P<0.05)$ (Table 1). Oct-4 expression did not correlate with sex or histological type $(P>0.05)$ (Table 1). Possible prognostic factors for gastric cancer were determined by Cox regression analysis (Table 2 ). The study showed that depth of invasion $(P=0.012)$, lymph node metastasis $(P=0.011)$, distant metastasis $(P=0.008)$, TNM stage $(P=0.009)$, and the level of Oct-4 expression
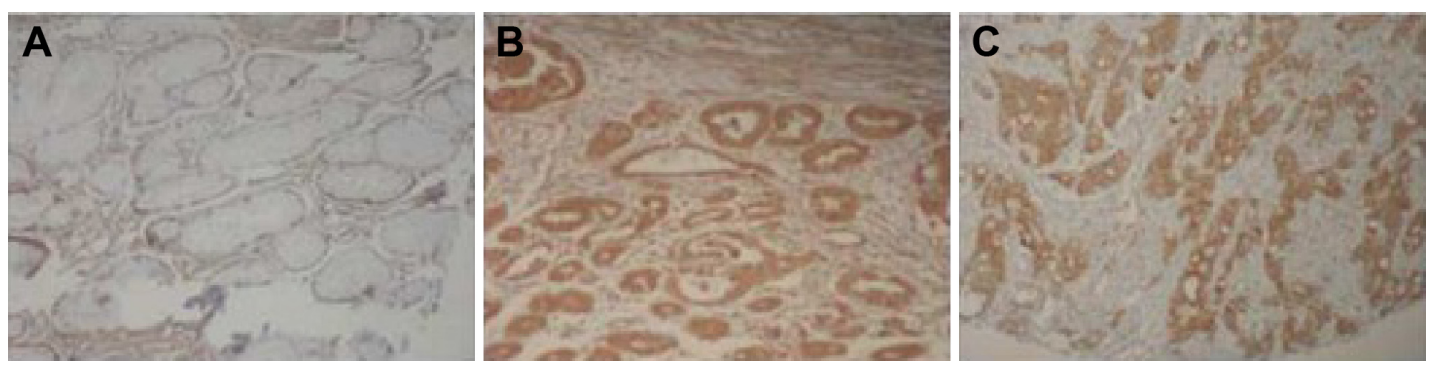

Figure I Immunohistochemical staining for Oct-4 in gastric cancer lesions and noncancerous tissues $(\mathrm{SP} \times 100)$.

Notes: (A) Oct-4 negative in noncancerous tissues; (B) Oct-4 was highly expressed in moderately differentiated adenocarcinoma; (C) Oct-4 was highly expressed in poorly differentiated adenocarcinoma. 
Table I Relationship of Oct-4 expression with pathological parameters of tumor

\begin{tabular}{|c|c|c|c|c|}
\hline \multirow[t]{2}{*}{ Clinical parameters } & \multicolumn{4}{|l|}{ Oct-4 } \\
\hline & Low, n (\%) & High, n (\%) & $t / \chi^{2} / r$ & $P$-value \\
\hline Age (years), mean \pm SD & $56.91 \pm 10.99$ & $61.22 \pm 12.66$ & 3.43 & 0.001 \\
\hline \multicolumn{5}{|l|}{ Sex } \\
\hline Male & $104(36.6)$ & $180(63.4)$ & 0.944 & 0.331 \\
\hline Female & $56(43.8)$ & $72(56.2)$ & & \\
\hline \multicolumn{5}{|l|}{ Location } \\
\hline Proximal & $40(47.6)$ & $44(52.4)$ & 3.507 & 0.173 \\
\hline Middle & $48(3 \mid .2)$ & $106(68.8)$ & & \\
\hline Distal & $72(4 I .4)$ & $102(58.6)$ & & \\
\hline \multicolumn{5}{|l|}{ Size } \\
\hline$<5 \mathrm{~cm}$ & $94(47.5)$ & $104(52.5)$ & 5.99 & 0.14 \\
\hline$\geq 5 \mathrm{~cm}$ & $66(30.8)$ & $148(69.2)$ & & \\
\hline \multicolumn{5}{|l|}{ Lauren classification } \\
\hline Intestinal & $163(73.1)$ & $60(26.9)$ & 136.2 & 0.0001 \\
\hline Diffuse & $37(17.4)$ & I $76(82.6)$ & & \\
\hline \multicolumn{5}{|l|}{ Histology } \\
\hline Papillary adenocarcinoma & $4(40.0)$ & $6(60.0)$ & 1.75 & 0.626 \\
\hline Tubular adenocarcinoma & $106(36.1)$ & $188(63.9)$ & & \\
\hline Mucinous adenocarcinoma & 14 (46.7) & $16(53.3)$ & & \\
\hline Signet-ring cell carcinoma & $36(46.2)$ & $42(53.8)$ & & \\
\hline \multicolumn{5}{|l|}{ Histologic differentiation } \\
\hline Well or moderately & $64(49.2)$ & $66(50.8)$ & 4.32 & 0.038 \\
\hline Poorly or undifferentiated & $96(34.0)$ & $186(66.0)$ & & \\
\hline \multicolumn{5}{|l|}{ Invasion depth } \\
\hline TI & $12(66.7)$ & $6(33.3)$ & 8.36 & 0.039 \\
\hline $\mathrm{T} 2$ & $42(48.8)$ & $44(5 \mid .2)$ & & \\
\hline $\mathrm{T} 3$ & $56(4 \mid .2)$ & $80(58.8)$ & & \\
\hline $\mathrm{T} 4$ & $50(29.1)$ & $122(70.9)$ & & \\
\hline \multicolumn{5}{|l|}{ TNM stages } \\
\hline I & I4 (77.8) & $4(22.2)$ & 14.06 & 0.003 \\
\hline II & $56(51.9)$ & $52(48.1)$ & & \\
\hline III & $78(33.6)$ & I54 (66.4) & & \\
\hline IV & $12(22.2)$ & $42(77.8)$ & & \\
\hline \multicolumn{5}{|l|}{ Lymph node metastasis } \\
\hline No & $102(48.6)$ & $108(5 \mathrm{I} .4)$ & 8.54 & 0.003 \\
\hline Yes & $58(28.7)$ & I44 (7I.3) & & \\
\hline \multicolumn{5}{|l|}{ Distant metastasis } \\
\hline No & $150(41.9)$ & $208(58.1)$ & 5.39 & 0.02 \\
\hline Yes & $10(18.5)$ & $44(81.5)$ & & \\
\hline
\end{tabular}

Note: Student's t-test was used.

Table 2 Multivariate analysis of the correlation between clinicopathological parameters and survival time in patients with gastric cancer

\begin{tabular}{|c|c|c|c|c|c|}
\hline Covariates & Coefficient & Standard error & HR & $95 \% \mathrm{Cl}$ for $\mathrm{HR}$ & $P$-value \\
\hline Age & 0.037 & 0.172 & 1.055 & $0.631-1.586$ & 0.764 \\
\hline Tumor location & 0.034 & 0.169 & 1.054 & $0.676-1.566$ & 0.821 \\
\hline Tumor size & 0.044 & 0.131 & 1.045 & $0.808-1.350$ & 0.740 \\
\hline Differentiation & 0.036 & 0.168 & 1.063 & $0.67 \mid-1.606$ & 0.747 \\
\hline Lauren's classification & 0.038 & 0.189 & 1.062 & $0.756-1.573$ & 0.676 \\
\hline Depth of invasion & 0.753 & 0.279 & 1.921 & $1.458-2.608$ & 0.012 \\
\hline Lymph node metastasis & 0.750 & 0.286 & 2.022 & $1.290-3.72 \mid$ & 0.011 \\
\hline Distant metastasis & 0.653 & 0.162 & 1.936 & $1.392-2.678$ & 0.008 \\
\hline TNM stage & 1.080 & 0.342 & 3.025 & $1.415-5.074$ & 0.009 \\
\hline Oct-4 expression & 0.924 & 0.271 & 2.567 & $1.475-2.563$ & 0.009 \\
\hline
\end{tabular}

Abbreviations: $\mathrm{Cl}$, confidence interval; $\mathrm{HR}$, hazard ratio. 
$(P=0.009)$ were all independent prognostic factors. However, the location of the tumor, tumor size, histological type, and differentiation had no prognostic value.

\section{Oct-4 expression was correlated with patient prognosis}

The 5-year survival rate for those with high Oct-4 expression (patients with stage I, II, or III disease) was significantly lower than that in patients with low Oct-4 expression. The cumulative 5-year survival rate was $92.9 \%$ in the low-expression group, but only $76.0 \%$ in the high-expression group $(P=0.001$, Figure 2) in stage I; the cumulative 5-year survival rate was $68.2 \%$ and $44.8 \%$ in the low- and high-expression group, respectively, $(P=0.0001$, Figure 3$)$ in stage II; and in stage III, the cumulative 5-year survival rate was $39.3 \%$ and $21.6 \%$ in the low- and high-expression group, respectively, $(P=0.0001$, Figure 4). For stage IV, the expression of Oct-4 did not correlate with the 5-year survival rate $(3.5 \%$ and $0 \%$ in the lowand high-expression group, respectively; $P=0.439$ ).

\section{Discussion}

Oct-4 was recently identified to be associated with tumorigenesis and malignant transformation of many cancers. Oct-4 induced dysplasia by inhibiting cellular differentiation. ${ }^{13}$ The expression of Oct-4 in mucosal tissues with severe gastritis, metaplastic/dysplastic transformation, and gastric cancer was significantly increased $(2 \%, 6 \%$, and $16 \%$, respectively), and the results suggested that Oct-4 plays a role in the early stages of cancer development. ${ }^{14}$ Chen et al $^{15}$ examined the

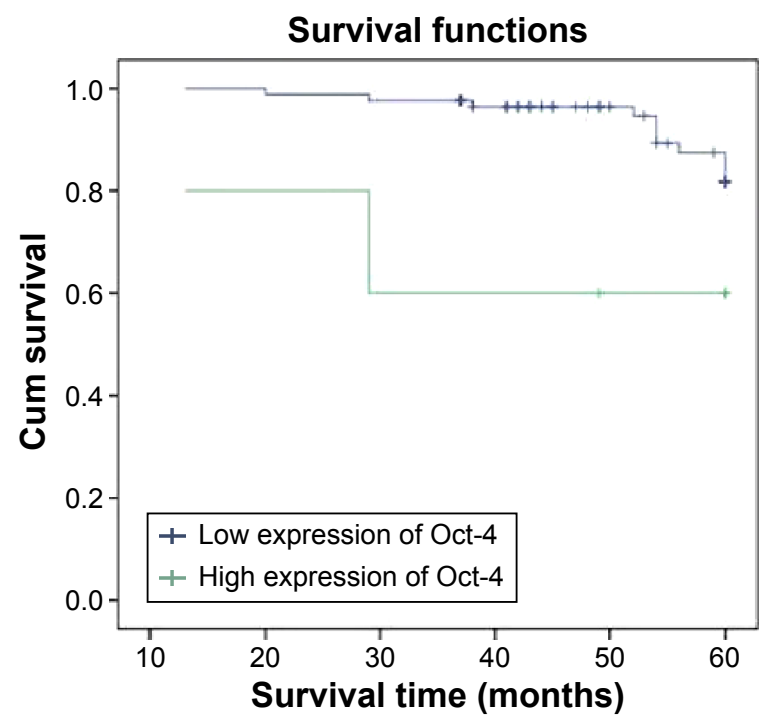

Figure 2 Kaplan-Meier curves with univariate analyses (log-rank) for patients with low Oct-4 expression versus those with high Oct-4 expression tumors in all gastric cancer in stage $I$.

Abbreviation: Cum, cumulative.

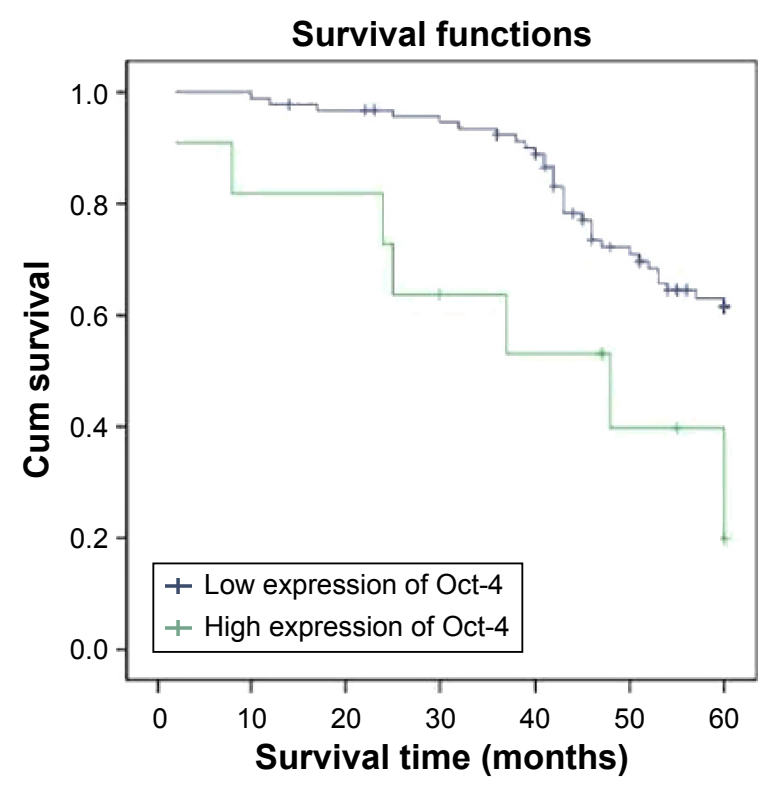

Figure 3 Kaplan-Meier curves with univariate analyses (log-rank) for patients with low Oct-4 expression versus those with high Oct-4 expression tumors in all gastric cancer in stage II.

Abbreviation: Cum, cumulative.

expression of Oct-4 in 62 gastric cancer cases using reverse transcription polymerase chain reaction and immunohistochemistry. The expression of Oct-4 was higher in gastric cancer tissues compared with the matching adjacent noncancerous tissues, and the expression of Oct-4 in gastric cancer was correlated with differentiation status, but not with age, sex, tumor size, TNM stage, depth of invasion, or lymph node metastasis. ${ }^{15}$ Little is known regarding the effect of Oct-4 as a potential biomarker of gastric cancer.

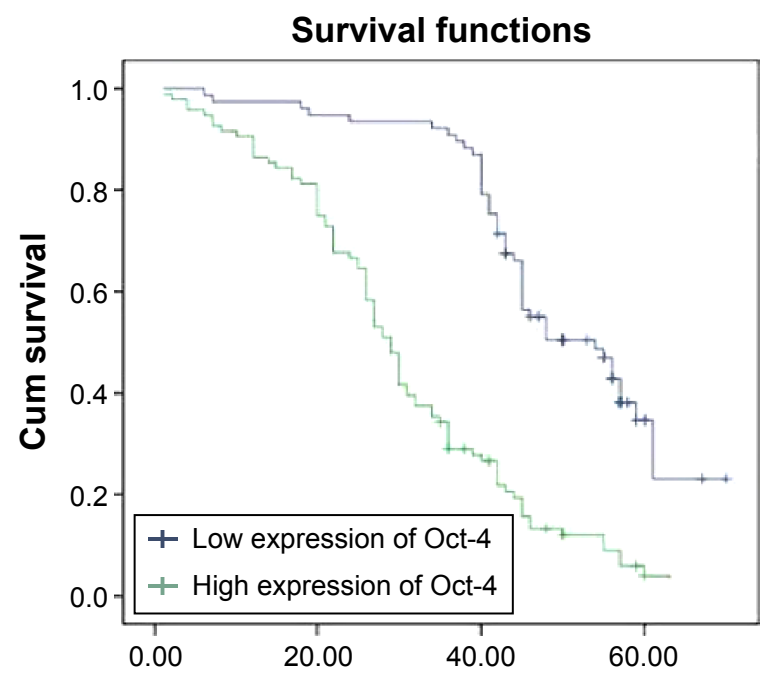

Figure 4 Kaplan-Meier curves with univariate analyses (log-rank) for patients with low Oct-4 expression versus those with high Oct-4 expression tumors in all gastric cancer in stage III.

Abbreviation: Cum, cumulative. 
The expression of Oct-4 by immunostaining is a useful tool in assessing its clinical applications as a marker of neoplasia. ${ }^{16,17}$ Therefore, in this study, we detected the expression of Oct-4 in gastric cancer using immunohistochemistry and assessed its relationship with clinicopathological parameters. The study identified that Oct- 4 was highly expressed in gastric cancer tissues compared with normal gastric tissues, and this was related significantly with prognosis. High expression of Oct-4 in gastric cancer cases was associated with age, tumor size, tumor location, depth of invasion, lymph node and distant metastasis, and TNM stage. The literature shows that the expression of Oct-4 was significantly associated with large tumor size and vascular invasion, and was an independent predictor of postoperative recurrence and poor prognosis of HCC..$^{18}$ Expression of Oct-4 was significantly associated with poor differentiation and recurrence of $\mathrm{HCC}$, and was an independent predictive factor in patients with HCC. ${ }^{19}$ Since the most important prognostic factor for gastric cancer is lymph node and distant metastasis, ${ }^{20,21}$ we analyzed the relationship between expression of Oct- 4 and prognosis of patients with gastric cancer (staged according to TNM criteria). We found that the expression of Oct-4 was associated with poor prognosis in stage I-III, but was not associated with poor prognosis in stage IV.

The present study suggests that expression of Oct-4 in gastric cancer tissues may play an important role in the progression and metastases of gastric cancer, has a potential role in tumorigenesis of gastric cancer, and is a new tumor marker with potential value in the diagnosis and treatment of gastric cancer. Oct- 4 might be a target of the $\beta$-catenin/ TCF-mediated downstream gene in Wnt-activated cells, and uncovering Oct-4 downstream targets could further elucidate its part in tumorigenesis and could be a new target to combat cancer. ${ }^{22}$

\section{Acknowledgment}

This work was supported by Zhejiang Provincial Medical Science Research Fund (grant 201337120).

\section{Author contributions}

Jiang WL and Zhang PF were equal contributors; Jiang WL and Zhang PF performed the majority of experiments and provided vital reagents and analytical tools and were also involved in writing the manuscript. Li GF and Wang XS provided the collection of all the human material in addition to providing financial support for this work. Dong JH and Wang YY designed the study and edited the manuscript.
All authors contributed toward data analysis, drafting, and revising the paper and agree to be accountable for all aspects of the work.

\section{Disclosure}

The authors report no conflicts of interest in this work.

\section{References}

1. Zhao ZS, Wang YY, Chu YQ, et al. SPARC is associated with gastric cancer progression and poor survival of patients. Clin Cancer Res. 2010;16:260-268.

2. Nichols J, Zevnik B, Anastassiadis K, et al. Formation of pluripotent stem cells in the mammalian embryo depends on the POU transcription factor Oct4. Cell. 1998;95:379-391.

3. Looijenga LH, Stoop H, de Leeuw HP, et al. POU5F1 (OCT3/4) identifies cells with pluripotent potential in human germ cell tumors. Cancer Res. 2003;63:2244-2250.

4. Tai MH, Chang CC, Kiupel M, et al. Oct4 expression in adult human stem cells: evidence in support of the stem cell theory of carcinogenesis. Carcinogenesis. 2005;26:495-502.

5. Zhang J, Li YL, Zhou CY, et al. Expression of octamer-4 in serous and mucinous ovarian carcinoma. J Clin Pathol. 2010;63(10):879-883.

6. Yuan F, Zhou W, Zou C, et al. Expression of Oct4 in HCC and modulation to wnt $/ \beta$-catenin and TGF- $\beta$ signal pathways. Mol Cell Biochem. 2010;343:155-162.

7. Wen J, Park JY, Park KH, et al. Oct4 and Nanog expression is associated with early stages of pancreatic carcinogenesis. Pancreas. 2010; 39:622-626.

8. Yasuda H, Tanaka K, Okita Y, et al. CD133, OCT4, and NANOG in ulcerative colitis-associated colorectal cancer. Oncol Lett. 2011;2:1065-1071.

9. Zhang D, Salto-Tellez M, Putti TC, et al. Reliability of tissue microarrays in detecting protein expression and gene amplification in breast cancer. Mod Pathol. 2003;16:79-84.

10. Lee HS, Cho SB, Lee HE, et al. Protein expression profiling and molecular classification of gastric cancer by the tissue array method. Clin Cancer Res. 2007;13:4154-4163.

11. Song LB, Liao WT, Mai HQ, et al. The clinical significance of twist expression in nasopharyngeal carcinoma. Cancer Lett. 2006;242: 258-265.

12. Fukuoka J, Fujii T, Shih JH, et al. Chromatin remodeling factors and BRM/BRG1 expression as prognostic indicators in non-small cell lung cancer. Clin Cancer Res. 2004;10:4314-4324.

13. Hochedlinger K, Yamada Y, Beard C, et al. Ectopic expression of Oct-4 blocks progenitor-cell differentiation and causes dysplasia in epithelial tissues. Cell. 2005;121:465-477.

14. Al-Marzoqee FY, Khoder G, Al-Awadhi H, et al. Upregulation and inhibition of the nuclear translocation of Oct-4 during multistep gastric carcinogenesis. Int J Oncol. 2012;41(5):1733-1743.

15. Chen Z, Xu WR, Qian H, et al. Oct-4, a novel marker for human gastric cancer. J Surg Oncol. 2009;99:414-419.

16. Cheng L. Establishing a germ cell origin for metastatic tumors using Oct-4 immunohistochemistry. Cancer. 2004;101(9):2006-2010.

17. Cheng L, Sung MT, Cossu-Rocca P, et al. Oct-4: biological functions and clinical applications as a marker of germ cell neoplasia. J Pathol. 2007;211:1-9

18. Yin X, Li YW, Zhang BH, et al. Coexpression of stemness factors Oct-4 and Nanog predict liver resection. Ann Surg Oncol. 2012;19: 2877-2887.

19. Dong Z, Zeng Q, Luo H, et al. Increased expression of Oct-4 is associated with low differentiation and tumor recurrence in human hepatocellular carcinoma. Pathol Res Pract. 2012;208:527-533.

20. Saito H, Fukumoto Y, Osaki T, et al. Prognostic significance of level and number of lymph node metastases in patients with gastric cancer. Ann Surg Oncol. 2007;14(5):1688-1693. 
21. Hidaka H, Eto T, Maehara N, et al. Comparative effect of lymph node metastasis classified by the anatomical site or by the number of nodes involved on prognosis of patients with gastric cancer. Hepatogastroenterology. 2008;55(88):2269-2272.
22. Li J, Li J, Chen B. Oct-4 was a novel target of Wnt signaling pathway. Mol Cell Biochem. 2012;362(1-2):233-240.

\section{Publish your work in this journal}

OncoTargets and Therapy is an international, peer-reviewed, open access journal focusing on the pathological basis of all cancers, potential targets for therapy and treatment protocols employed to improve the management of cancer patients. The journal also focuses on the impact of management programs and new therapeutic agents and protocols on

\section{Dovepress}

patient perspectives such as quality of life, adherence and satisfaction. The manuscript management system is completely online and includes a very quick and fair peer-review system, which is all easy to use. Visit http://www.dovepress.com/testimonials.php to read real quotes from published authors.

Submit your manuscript here: http://www.dovepress.com/oncotargets-and-therapy-journal 